\title{
Content Delivery Networks in Cross-border e-Commerce
}

\author{
Artur Strzelecki \\ Department of Informatics \\ University of Economics in Katowice \\ Katowice, Poland
}

\begin{abstract}
Cross-border e-commerce has been growing in recent years. Purchasing goods from abroad is getting easier due to global deliveries, well-known payment methods and decreasing language barriers. Content Delivery Network (CDN) is a technical solution. Deploying CDN for cross-border e-commerce can improve performance and consumer experience. In this paper, four sets of cross-border online stores, containing together 57 e-commerce stores, are examined. Each set is a group of online stores operating in many European markets with different Domain Name System (DNS) settings. Two sets use Cloudflare CDN and its DNS server. Other two sets use country DNS server settings without CDN. Results show that DNS lookup time significantly decrease for cross-border users when online stores are using a CDN, improving overall website time load. Increase of speed for resolving domain names is on average from $40 \mathrm{~ms}$ to $5 \mathrm{~ms}$. No significant improvement was observed for user in the same country location.
\end{abstract}

Keywords-e-Commerce; cross-border e-commerce; content delivery networks; DNS lookup time; time to first byte

\section{INTRODUCTION}

Cross-border e-commerce (CBEC) is a type of trade between retailers and customers, in which retailers sell goods online using an e-commerce store. Retailers selling online are called e-tailers. Customers purchase goods using a web browser on their computers or mobile devices. As the online stores and customers are from two different countries, the orders need to be sent from one country to another country, thus crossing a border [1]. This definition is applicable in the European Union (EU) [2], whereas in China cross-border e-commerce is often considered as trade between different areas like North China and South China, or pilot areas [3].

One of the key factors in e-commerce influencing conversion rate in an online store is speed of its website [4]. When the response time increases, it is negatively influencing the conversion rate. Shorter response time and overall faster site speed positively influence the conversion rate. Problem of website load time is complex [5]. There is no single factor that decides how fast a website will load. Load time depends on three main areas. First, the server prepares data which will be sent to the online visitor. Second, there is a transmission or download between server and online visitor. Third, the software used for rendering incoming data, usually a web browser, needs time to render the whole website and show it to the online visitor. Each area can be optimized in its own way.
First, the server response time is influenced by time to first byte (TTFB) [6], Content Delivery Networks [7], disk caching [8], keep alive [9], HTTP/2 [10], code acceleration, varnish/caching [11], accelerated mobile pages [12], etc. Second, the download time (transmission) is influenced by size of image files [13], the proper type of image files [14], (e.g. using the JPG for pictures instead of PNG), minification of text objects like JavaScript scripts, CSS files and HTML files, HTTP compression [15], header expiration date [16], CSS sprites [17], image scaling for mobile screens [18], cookie-less domain [19], etc. Third, the rendering time is influenced by proper order of loaded CSS files and JS scripts [16], parallel connection [20] , HTML optimization [21], lazy load for images [22], DNS prefetch [23], prerender and prefetch of files and URLs [24], CSS optimization [25], JS optimization [26], etc.

Cross-border e-commerce mainly exists in long range distances, at least from one country to another country when EU area is considered. The same is for online store visitors, when they browse e-commerce from another country. Data that needs to be sent from server to online visitor needs to be sent for a long distance. This influences negatively the website load time. The longer the distance between an online store and its customer, the longer the website load time. Usually server of an online store is located in the same country where most online customers of this store live. Cross-border e-commerce expands distances between data servers and customers that is why they are located further than before. Load time is slower compared to the load time of an online store located closer to the customer. Based on this analysis a research question is formulated:

RQ: What are the ways of increasing website load time in cross-border e-commerce?

The goal of this paper is to hypothesize that using content delivery network, - a factor that influences server response time and DNS lookup time, - can decrease load time in crossborder e-commerce. The rest of this paper is organized as follows. In the next section, a review of the relevant literature is undertaken. Then the study setup and hypothesis development are described and, following this, the results are presented and discussed. Finally, conclusions are drawn. 


\section{LITERATURE REVIEW}

\section{A. Content Delivery Networks}

The content delivery networks (CDNs) technique is one of the successful virtual networks rapidly developed over the last two decades with the specific advantage of optimizing the Internet. Nowadays, the CDN has become one of the most important parts of the Internet architecture for content distribution.

One direction is to show how CDNs has positively influenced business and companies. CDNs improve network performance and offer fast and reliable applications and services by distributing content to cache servers located close to users. It is a method for reducing response times experienced by Internet users through locating multiple servers close to clients. CDNs act as trusted overlay networks that offer highperformance delivery of common Web objects, static data, and rich multimedia content by distributing the content load among servers that are close to the clients. CDN benefits include reduced origin server load, reduced latency for end users, and increased throughput [7].

Content delivery networks are taking into account different variables such as caching hit ratios, network latency, number of surrogates, and server capacity [27]. Main research areas in the field of CDN are pointing out the motivations, analyzing the existing strategies for replica placement and management, server measurement, best fit replica selection and request redirection [28]. CDN is a payable service. Different service type architectures for CDNs are available together with proposed pricing schemes to complement this architecture and provide fair service to the subscribed publishers [29]. There is a need of a balance between the costs for web content providers and the quality of service for web customers in terms of CDNs [30].

Another direction is to improve the existing network solutions and build new architecture and solutions for CDNs. The innovative technologies in CDNs are highlighted and their evolution triggered by ever newer emerging applications is presented. By presenting an in-depth discussion about the architecture, challenges, and applications of CDNs, their importance for the future Internet is demonstrated [31]. In CDNs predictive content distribution strategies are inspired by methods developed in the recommender systems area. Different content placement strategies are outlined based on the observed user consumption patterns and their applicability in the state of the art CDNs [32]. Cloud-based CDNs take advantage of the geographical availability and the pay-as-yougo model of cloud platforms [33].

Thoroughly understanding the CDN industry from different aspects including market choice, technology, performance, tendency and infrastructure is indispensable to future Internet. Comprehensive studies on challenges to the existing commercial CDNs are provided [34]. Different CDN architectures have different relative strengths and weaknesses. The role of location, the growing complexity of the CDN ecosystem, and their relationship to and implications for interconnection markets is highlighted [35].

\section{B. Cross-Border e-Commerce}

CBEC is strongly developing in China. One area of works is to analyze how logistics in CBEC works in China. With the rapid development of cross-border e-commerce, the demand for and importance of cross-border logistics service also increase [36]. A review of different 32 studies on how CBEC logistics work in China was made by Giuffrida et al. [37]. They identified a set of possible development areas, including distribution network design, i.e. deciding how to shape the CBEC distribution structure, and logistics outsourcing, i.e. determining whether to manage logistics activities in-house or through third parties. The impact of cross-border e-commerce on international trade in the context of China is investigated, mainly from the perspective of transaction cost economics in conjunction with the traditional comparative advantage model by analyzing information cost, negotiation cost, transportation cost, tariffs and middlemen cost separately [38].

Three types of supply chain localization in cross-border e-commerce for export markets (sales, warehousing, and R\&D localization) are identified. The three localization strategies serve as the driving force and the main business model innovation in cross-border e-commerce [39]. China's e-commerce cross-border logistics main modes are: international postal packet, international express, overseas warehouse, cross-border logistics, third party logistics, bonded zone and free trade zone, etc., however, CBEC logistics is not yet developed as well like CBEC [40].

Other issues concerning Chinese CBEC are described in different works. Cross-border e-commerce should include some mechanisms of government policies [41]. Chinese CBEC businesses can be focused more on the service and cost control of supply chain downstream through strategic cost control measures [42]. Traditional e-commerce recommender system is not suitable for the CBEC situation, thus there is a need of a personalized e-commerce recommender system to meet the needs of cross border e-commerce [43].

CBEC industry in China generally presents a tendency of solid growth; it has had a relatively stable situation for logistics facilitation but a drastic fluctuation in customs facilitation, has gradually shifted to competing for cheaper and more efficient marketing techniques as well as channels, and has experienced a remarkable amelioration of risk magnitude [44]. The relationship between technological progress, cross-border e-commerce and the establishment of global digital customs can be explored from the dimensions of the latest development of new digital infrastructure [45]. Customer satisfaction index system in cross-border e-commerce was constructed which follow the principle of objectivity, comprehensiveness and dynamic [46] and a model of consumer behavior was created after incident in well-known Chinese market place which operates on cross-border market [47].

Outside China different aspects of CBEC have already been described. Barriers in cross-border e-commerce between USA and Canada in duty regimes and tax laws have been studied [48]. A conception of an integrator in cross-border e-commerce was proposed and its main task is to integrate the whole supply chain [49]. Different characteristics like gender, education, computer skills, nationality and trust in reviews positively 
influence the CBEC [50]. A novel platform architecture to improve the pluggability of e-commerce services was proposed and checked on the example of a trade compliance service for cross-border retail [51]. Study on cross-border e-commerce in European environment and description of its current status emphasise how e-tailers should be prepared for sustainable cross-border e-commerce in the EU [52].

\section{MATERIALS AND METHODS}

This section contains research method and hypotheses development. Research method is constructed from four different tests, which will support or not the stated hypotheses.

The subject for this study are the four sets of cross-border online stores. Each set is owned by one company. The first set of 8 online stores is owned by Babyaisle, a Polish company which sells goods for babies and kids in online stores. Detailed information of countries and languages of this set is in Table I. The second set of 16 online stores is owned by Eobuwie, a Polish company selling shoes, accessories and handbags in online stores. Detailed information of countries and languages of this set is in Table II. The third set of 18 online stores is owned by Oponeo, a Polish company that sells tires in online stores. Detailed information of countries and languages of this set is in Table III. The fourth set of 15 online stores is owned by Babymarkt, a German company selling goods for babies and kids in online stores. Detailed information of countries and languages of this set is in Table IV. After launching an online store for national market, the owner of each set decided to create an offer for foreign customers by launching the same store in another language and country versions.

There are two different approaches for launching another language and country version. The new language and country version can be launched in a subdirectory of a main domain name. Usually it is observed for well-known global brands which have ".com" domain names and the version of an online store is localized in a subfolder. The second approach, used in this case, is to run each language and country version in separate country-coded top-level domain.

Store owners have launched a copy version of its online store but have localized for different countries. For each set, an e-commerce engine, backend engine and database are the same for every language and country version. However, frontend emulates different languages and localized country versions. By localization it means currency conversion, IP detection for delivery purpose and different sets of reviews and opinions given by consumers from each targeted country. These four sets of online stores now have different configurations in terms of using CDNs. Specific configuration is shown in Tables I to IV.

Three tools will be used to measure DNS lookup time, connect time and time-to-first-byte in different sets. DNS lookup time measurement is the time spent resolving the DNS name to an IP address. Typically, this is measured from a DNS server located near the client that wants to communicate with a server [53]. Connection time measurement is the time required for setting up a connection from a client to a Web server. This delay is the time needed to establish the connection [53]. Timeto-first-byte measurement is the amount of time from when the client sends the request (GET command) until it sees the first byte back from the server. This is a single round trip across the Internet [53].

First is the DNSPerf [https://www.dnsperf.com/] which is DNS performance analytics and comparison tool. This tool will show speed results of DNS lookup time for different online store versions. DNSs will be queried from different geographical locations.

The second tool is a script written for unix systems using the dig command. The script will be programmed to test simultaneously the end-client speed for resolving DNS names. The code is based on [54] proposition. The second test will be repeated 24 times, for each local DNS available for countrycoded top-level domain (ccTLD). Unfortunately, domain suffix ".eu" and ".com" are not country coded - the first represents all EU area and the second is a generic domain. There is no specific DNSs for “.eu” or ".com”.

The third tool is a curl command deployed under unix/macos terminal service. Command is configured to measure the lookup time, connect time and time-to-first-byte. Important value to pay attention is the time-to-first-byte [6], which informs how long it took for the content to be sent back to browser to start processing the page. The code is based on [55] proposition. This tool will show the lookup time, connect time and time-to-first-byte. The fourth test will be repeated for each online store from one geographical location - the author's location.

Based on this research method two hypotheses are proposed:

H1. Deploying e-commerce on CDN will decrease DNS lookup time in localized e-markets for cross-border visitors.

H2. Deploying e-commerce on CDN will decrease time-tofirst-byte value in localized e-markets for cross-border visitors.

TABLE I. LOCALIZED VERSIONS OF BABYAISLE ONLINE STORES

\begin{tabular}{|l|l|l|l|}
\hline Domain name & $\begin{array}{l}\text { Targeted } \\
\text { country }\end{array}$ & Language & CDN \\
\hline babyland.pl & Poland & Polish & CloudFlare \\
\hline babyaisle.de & Germany & German & CloudFlare \\
\hline babyaisle.dk & Denmark & Danish & CloudFlare \\
\hline babyaisle.eu & $\begin{array}{l}\text { Other EU } \\
\text { countries }\end{array}$ & English & CloudFlare \\
\hline babyaisle.fr & France & French & CloudFlare \\
\hline babyaisle.es & Spain & Spanish & none \\
\hline babyaisle.it & Italy & Italian & none \\
\hline babyaisle.cz & $\begin{array}{l}\text { Czech } \\
\text { Republic }\end{array}$ & Czech & none \\
\hline
\end{tabular}


Data contains the four sets of online stores. For each set, usually a store in each particular country is set up with the core domain name, reflecting name of the company or brand. Core names are babyland, oponeo and pinkorblue. Eobuwie for each country has launched an online store with local translation of "efootwear". First set for Babyland contains 8 online stores.

In Table I there is a summary of the current configuration for each localized version in the first set. From a set of eight domain names, five (.pl, .de, .dk, .eu, and .fr) are using CDN from CloudFlare [https://www.cloudflare.com/]. Currently CloudFlare is served for more than 13 million domain names and has 165 data center locations. Three domain names are not using CDNs. They are hosted in Oktawave, Polish public cloud service.

To use CDN from CloudFlare a domain name must set for their DNS names. During configuration of the CloudFlare service, it shows to which DNSs it should be set. CloudFlare (CF) is a well-recognized CDN, DNS, DDoS protection and security service. Switching domain name into CF it allows measuring changes in DNS speed resolving and load time for a website.

In Table II, a summary of the current configuration for each localized version in the second set is presented. In this set all of the 16 online stores from Eobuwie owner are using CDN from CloudFlare.

TABLE II. LOCALIZED VERSIONS OF EOBUWIE ONLINE STORES

\begin{tabular}{|l|l|l|l|}
\hline Domain name & Targeted country & Language & CDN \\
\hline eobuwie.com.pl & Poland & Polish & CloudFlare \\
\hline eschuhe.de & Germany & German & CloudFlare \\
\hline eobuv.com.ua & Ukraine & Ukrainian & CloudFlare \\
\hline efootwear.eu & Other EU countries & English & CloudFlare \\
\hline chaussures.fr & France & French & CloudFlare \\
\hline zapatos.es & Spain & Spanish & CloudFlare \\
\hline escarpe.it & Italy & Italian & CloudFlare \\
\hline eobuv.cz & Czech Republic & Czech & CloudFlare \\
\hline ecipo.hu & Hungary & Hungarian & CloudFlare \\
\hline eobuv.com & Russia & Russian & CloudFlare \\
\hline eobuv.sk & Slovakia & Slovakian & CloudFlare \\
\hline eavalyne.lt & Lithuania & Lithuanian & CloudFlare \\
\hline epantofi.ro & Romania & Romanian & CloudFlare \\
\hline eskor.se & Sweden & Swedish & CloudFlare \\
\hline epapoutsia.gr & Greece & CloudFlare \\
\hline obuvki.bg & Bulgarian & CloudFlare \\
\hline
\end{tabular}

TABLE III. LOCALIZED VERSIONS OF OPONEO ONLINE STORES

\begin{tabular}{|c|c|c|c|}
\hline Domain name & Targeted country & Language & CDN \\
\hline oponeo.pl & Poland & Polish & none \\
\hline oponeo.de & Germany & German & none \\
\hline oponeo.sk & Slovakia & Slovak & none \\
\hline oponeo.co.uk & United Kingdom & English & none \\
\hline oponeo.fr & France & French & none \\
\hline oponeo.es & Spain & Spanish & none \\
\hline oponeo.it & Italy & Italian & none \\
\hline oponeo.cz & Czech Republic & Czech & none \\
\hline oponeo.hu & Hungary & Hungarian & none \\
\hline oponeo.ch & Switzerland & German & none \\
\hline oponeo.com & United States & English & none \\
\hline oponeo.ie & Ireland & Irish & none \\
\hline oponeo.nl & The Netherlands & Dutch & none \\
\hline oponeo.at & Austria & German & none \\
\hline oponeo.com.tr & Turkey & Turkish & none \\
\hline pneus-oponeo.ch & Switzerland & French & none \\
\hline pneus-oponeo.be & Belgium & French & none \\
\hline banden-oponeo.be & Belgium & Dutch & none \\
\hline
\end{tabular}

In Table III there is a summary of the current configuration for each localized version in the third set. In this set all of the 18 online stores from Oponeo owner are using own DNS based on the Polish domain name and are not using any CDNs. Oponeo has two language versions of online stores for Switzerland (German and French) and two language versions for Belgium (French and Dutch).

Table IV contains a summary of the current configuration for each localized version in fourth set. In this set all of the 15 online stores from Babymarkt owner are using own DNS based on German domain name and are not using any CDNs. 
TABLE IV. LOCALIZED VERSIONS OF BABYMARKT ONLINE STORES

\begin{tabular}{|l|l|l|l|}
\hline Domain name & Targeted country & Language & CDN \\
\hline pinkorblue.pl & Poland & Polish & none \\
\hline babymarkt.de & Germany & German & none \\
\hline pinkorblue.dk & Denmark & Danish & none \\
\hline baby-markt.com & Other EU countries & English & none \\
\hline roseoubleu.fr & France & French & none \\
\hline rosaoazul.es & Spain & Spanish & none \\
\hline pinkorblue.it & Italy & Italian & none \\
\hline pinkorblue.cz & Czech Republic & Czech & none \\
\hline baby-markt.at & Austria & German & none \\
\hline baby-markt.ch & Switzerland & German & none \\
\hline pinkorblue.be & Belgium & Dutch & none \\
\hline pinkorblue.fi & Finland & Finnish & none \\
\hline pinkorblue.nl & The Netherlands & Dutch & none \\
\hline pinkorblue.no & Norway & Norwegian & none \\
\hline pinkorblue.se & Sweden & Swedish & none \\
\hline
\end{tabular}

\section{RESULTS}

In the first test done in DNSPerf, each domain name was checked from 50 different locations across Europe. Fig. 1 presents results in boxplot for DNS response times for every location for each online store in each set.

Brief results from the first test show that DNS lookup time for domains using CloudFlare DNSs is faster than for the domains not using it. Detailed boxplot statistics are in Table V.

The second test is done by using console window with the terminal. The test checks how fast for local client were the DNSs. The author used this script to do the test.

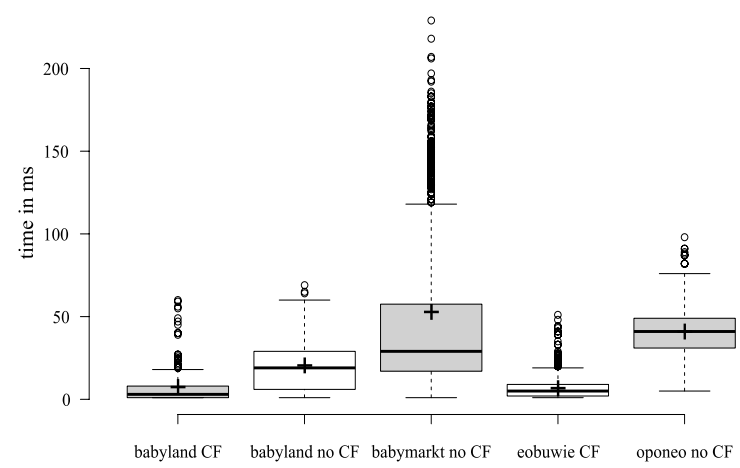

Fig. 1. Boxplot Results for Each Set of Online Stores. Babyaisle is Divided into Two Metrics, one with CF, the Second - without CF.
TABLE V. BOXPLOT STATISTICS FOR DNS LOOKUP TIME

\begin{tabular}{|l|l|l|l|l|l|}
\hline & $\begin{array}{l}\text { babyland } \\
\text { CF }\end{array}$ & $\begin{array}{l}\text { babyland no } \\
\text { CF }\end{array}$ & $\begin{array}{l}\text { babymar } \\
\text { kt }\end{array}$ & $\begin{array}{l}\text { eobuwi } \\
\text { e }\end{array}$ & $\begin{array}{l}\text { opone } \\
\text { o }\end{array}$ \\
\hline Upper whisker & 18.00 & 60.00 & 118.00 & 19.00 & 76.00 \\
\hline 3rd quartile & 8.00 & 29.00 & 57.50 & 9.00 & 49.00 \\
\hline Median & 3.00 & 19.00 & 29.00 & 5.00 & 41.00 \\
\hline 1 st quartile & 1.00 & 6.00 & 17.00 & 2.00 & 31.00 \\
\hline Lower whisker & 1.00 & 1.00 & 1.00 & 1.00 & 5.00 \\
\hline $\begin{array}{l}\text { Nr. of data } \\
\text { points }\end{array}$ & 249.00 & 147.00 & 744.00 & 850.00 & $\begin{array}{l}886.0 \\
0\end{array}$ \\
\hline Mean & 7.39 & 20.42 & 52.78 & 6.68 & 40.91 \\
\hline
\end{tabular}

for domain in babyaisle.es babyaisle.it babyaisle.cz babyaisle.de babyaisle.dk babyaisle.fr babyaisle.eu babyland.pl; do $\backslash$

custom_dns $=\$($ dig $\quad @$ custom-IP $\quad \$$ ddomain $\} \quad$ awk '/msec/ $\left.\{\text { print } \$ 4\}^{\prime}\right) ; \backslash$

cloudflare_dns $=\$($ dig @1.1.1.1 \$\{domain $\} \quad$ awk '/msec/\{print $\left.\$ 4\}^{\prime}\right) ; \backslash$

printf "\$\{domain $\backslash$ dCloudFlare DNS \$\{cloudflare_dns\}ms $\downarrow$ Custom DNS \$\{custom_dns\}ms $n^{\prime \prime} ; \backslash$

done

TABLE VI. CCTLD CUSTOM DNS VS CLOUDFLARE DNS FROM AUTHOR'S ORIGIN LOCATION (PL)

\begin{tabular}{|l|l|l|l|l|l|}
\hline No. & ccTLD & DNS IP & $\begin{array}{l}\text { Domain } \\
\text { name }\end{array}$ & $\begin{array}{l}\text { CloudFlare } \\
\text { DNS }\end{array}$ & $\begin{array}{l}\text { Custom } \\
\text { DNS }\end{array}$ \\
\hline 1 & ES & 80.66 .120 .34 & babyaisle.es & $48 \mathrm{~ms}$ & $113 \mathrm{~ms}$ \\
\hline 2 & IT & 87.241 .40 .194 & babyaisle.it & $46 \mathrm{~ms}$ & $101 \mathrm{~ms}$ \\
\hline 3 & CZ & 81.30 .229 .149 & babyaisle.cz & $44 \mathrm{~ms}$ & $100 \mathrm{~ms}$ \\
\hline 4 & DE & 62.8 .159 .193 & babyaisle.de & $46 \mathrm{~ms}$ & $81 \mathrm{~ms}$ \\
\hline 5 & DK & 195.137 .178 .10 & babyaisle.dk & $46 \mathrm{~ms}$ & $63 \mathrm{~ms}$ \\
\hline 6 & FR & 80.14 .75 .5 & babyaisle.fr & $44 \mathrm{~ms}$ & $137 \mathrm{~ms}$ \\
\hline 7 & PL & 212.87 .229 .67 & babyland.pl & $47 \mathrm{~ms}$ & $45 \mathrm{~ms}$ \\
\hline 8 & UA & 91.211 .213 .10 & eobuv.com.ua & $48 \mathrm{~ms}$ & $133 \mathrm{~ms}$ \\
\hline 9 & LT & 86.38 .173 .114 & eavalyne.lt & $52 \mathrm{~ms}$ & $86 \mathrm{~ms}$ \\
\hline 10 & RO & 195.189 .150 .37 & epantofi.ro & $52 \mathrm{~ms}$ & $140 \mathrm{~ms}$ \\
\hline 11 & SE & 85.30 .174 .198 & eskor.se & $47 \mathrm{~ms}$ & $142 \mathrm{~ms}$ \\
\hline 12 & GR & 195.130 .67 .4 & epapoutsia.gr & $48 \mathrm{~ms}$ & $154 \mathrm{~ms}$ \\
\hline 13 & BG & 195.234 .236 .34 & obuvki.bg & $55 \mathrm{~ms}$ & $156 \mathrm{~ms}$ \\
\hline 14 & HU & 91.83 .165 .219 & oponeo.hu & $48 \mathrm{~ms}$ & $151 \mathrm{~ms}$ \\
\hline 15 & CH & 62.202 .3 .102 & oponeo.ch & $48 \mathrm{~ms}$ & $98 \mathrm{~ms}$ \\
\hline 16 & SK & 92.240 .244 .8 & oponeo.sk & $48 \mathrm{~ms}$ & $123 \mathrm{~ms}$ \\
\hline 17 & TR & 213.128 .64 .149 & oponeo.com.tr & $49 \mathrm{~ms}$ & $155 \mathrm{~ms}$ \\
\hline 18 & UK & 95.172 .66 .6 & oponeo.co.uk & $55 \mathrm{~ms}$ & $118 \mathrm{~ms}$ \\
\hline 19 & IE & 86.43 .81 .177 & oponeo.ie & $47 \mathrm{~ms}$ & $134 \mathrm{~ms}$ \\
\hline 20 & NL & 145.131 .137 .117 & pinkorblue.nl & $48 \mathrm{~ms}$ & $151 \mathrm{~ms}$ \\
\hline 21 & AT & 188.118 .227 .21 & baby-markt.at & $48 \mathrm{~ms}$ & $119 \mathrm{~ms}$ \\
\hline 22 & BE & 91.183 .58 .171 & pinkorblue.be & $47 \mathrm{~ms}$ & $152 \mathrm{~ms}$ \\
\hline 23 & FI & 83.102 .69 .175 & pinkorblue.fi & $49 \mathrm{~ms}$ & $147 \mathrm{~ms}$ \\
\hline 24 & NO & 141.0 .79 .138 & pinkorblue.no & $52 \mathrm{~ms}$ & $168 \mathrm{~ms}$ \\
\hline
\end{tabular}


The first line defines domain names to check. This script was launched four times, for each set in this study. The version presented above is prepared for the first set of online stores. The second line checks with dig command custom DNS. In Table VI there is a list of local DNSs for each ccTLD in all four sets. List of publicly available DNS by country is at https://public-dns.info. For the test one DNS was chosen for each ccTLD - the one that was first on the list. Being first means that it was recently checked and was valid. The third line checks CloudFlare DNS, and the fourth line prints the results on the screen.

The goal of this test is to create a reversed route from the author's origin location (PL) to DNS in another country. It will emulate the same behavior when an online visitor from one country is connecting to an online store from another. Additionally, for comparison, the script is checking connection time for CloudFlare DNS.

The third test is done by script based on curl command. The script is checking how fast the first byte is sent from server to user and what is the time-to-first-byte. This script is similar to the one mentioned above. The code lines are the following:

for domain in \$domain_list; do \

$t t f b=\$($ curl $\quad-o \quad / d e v / n u l l \quad-s \quad-w$ "Lookup: $\backslash \%\{$ time_namelookup/ $\backslash$ Connect $: \backslash \%\{$ time_connect $\backslash t$ TTFB: $\backslash$ \% $\{$ \{time_starttransfer $\backslash$ CCode $: \backslash \%\{$ response_code $\backslash t I P: \backslash$ t\%\{remote_ip\} $\overline{\mathrm{n}}$ " https://\$\{domain\}); $\backslash$

$$
\text { printf } " \$\{\text { domain } \backslash t \$\{t t f b\} \vee n ">>\text { list.txt } ; \backslash
$$

done

Curl is using one location for this test - the one where the computer is connected. Variables measured via curl are:

- $\%\{$ time_namelookup $\}$ - shows the time (in seconds) it took from the start until the name resolving was completed. This is considered as lookup time.

- $\%\{$ time_connect $\}$ - shows the time (in seconds) it took from the start until the TCP connect to the remote host (or proxy) was completed. This is considered as connect time.

- $\%\{$ time_starttransfer $\}$ - shows the time (in seconds) it took from the start until the first byte was just about to be transferred. This is considered as time-to-first-byte (TTFB).

In Appendix all 57 domains from four sets are listed, with lookup time, connect time, TTFB times for each domain name, together with the current IP address.

\section{DISCUSSION}

Results showed that the proposed method for improving website load time positively works for the DNS lookup time. For the tests the author took respectively 8, 16, 18, and 15 similar domain names belonging to four different owners. Each domain is an online store targeted for specific European market.

Results, given by DNSPerf, revealed that setting DNS from CloudFlare significantly improved DNS lookup time. DNS lookup time for domains using CF was, on average, 4 times faster for Babyaisle online stores belonging to the first set, comparing to the other online stores from this set, not using CF. Average DNS lookup time for domains on CF was $7.39 \mathrm{~ms}$ whereas the average time for domains on dns.home.pl was $20.32 \mathrm{~ms}$. In the second set, an average DNS lookup time for Eobuwie, where all of them are located in CF DNS, is $6.68 \mathrm{~ms}$. In the third set, an average DNS lookup time for Oponeo, for the online stores not using CF or any other CDN, is $40.91 \mathrm{~ms}$. In the fourth set, average DNS lookup time for Babymarkt, for the online stores not using CF or any other CDN, is $52.78 \mathrm{~ms}$.

Results, given by script using dig command, revealed that setting DNS from CF significantly improved DNS lookup time from the client point of view. DNS lookup time for each domain, except ".pl", using CF was, on average, 2 to 3 times faster than for the domain set and its localized DNS. Average time for domains on $\mathrm{CF}$ using dig script was $48.4 \mathrm{~ms}$ whereas the average time for the domain and its localized DNS was 123.6 ms. Results for ".pl" domain were at each trial almost identical - around $46 \mathrm{~ms}$. This is because the tested ".pl" domain is in the same country where all the tests took place. Results given by DNSperf and the dig command support first hypothesis: Deploying e-commerce on CDN will decrease DNS lookup time in localized e-markets for cross-border visitors.

The third test with the use of curl command does not support the second hypothesis. This is because of two reasons. First, the test was run from one computer in one geographical location, however, results, even for online stores in the same set were different in terms of the lookup time, connect time and time-to-first-byte. The expectation was that online stores with the same configuration, location and backend engine would show similar results. This could be affected by testing real, living websites. Online load is different during the day and has some rise and falls depending on number of actual online visitors, and there are many other factors that influence the network performance and website load times. Some of them are mentioned in the introduction section.

Second, the average value of TTFB for each set is different. For Babyaisle is $1484 \mathrm{~ms}$, for Eobuwie is $407 \mathrm{~ms}$, for Oponeo is $729 \mathrm{~ms}$ and for Babymarkt is $567 \mathrm{~ms}$. It shows that TTFB strongly depends on backend engine and server configuration, instead of DNS setting and using CF. For instance, Babyaisle is using $\mathrm{CF}$ and has the fastest DNS lookup times, whereas its TTFB is the lowest from all four sets.

\section{A. Contributions}

In recent years, online transactions in cross-border e-commerce have become an essential part of the European e-market and have shown great potential. Because of some uncertainty in cross-border e-commerce, customers search for factors that can reduce the risk of buying cross-border. Online store owners can show that they recognize and carefully treat customers from abroad. This study empirically explored two factors that could improve website load time in cross-border e-commerce. There are two main findings. First, there are DNSs which have different lookup time. Lower lookup time means faster response. CloudFlare seems to be the fastest DNS service that can be used for cross-border e-commerce. Second, 
the time-to-first-byte is a metric that has different results for each online store. Curl shows detailed scores for this metric in seconds, but these results prove that time-to-first-byte strongly depends on e-commerce engine and server configuration. These findings have significant theoretical and practical implications.

This research can contribute to the literature on e-commerce behavior. Contribution relates to the consumer experience. If a consumer experiences faster load time for online store, it positively influences his readiness for making transactions. The results of the study suggest using faster DNS for cross-border e-commerce. In cross-border e-commerce, except shipment to another country, different language and currency, there is website load time factor, which can be taken into consideration when the online store goes to cross-border trade.

From the point of view of sustainability, this approach decreases usage of internet network. Customer only needs to connect to the closest network node for resolving DNS. Network load is lower and eventually the network traffic is sustainable.

\section{B. Practical Implications}

This study also yields several direct managerial implications. First, online stores have possibility to improve site performance in specific circumstances for cross-border e-commerce. This can be improved by starting using CDN service. Usually this kind of service is easy to launch, and costs are reasonable. Second, research method shows that this approach only works for online visitors from other countries. Test results using dig command revealed that using $\mathrm{CDN}$ in the same country does not influence DNS lookup time significantly.

\section{Limitations and Further Research}

This study has several limitations. First, the study was conducted in only three industries (baby goods, shoes and tires) and author only collected data from 57 online stores. However, all the online stores owned by four merchants' groups (Babyaisle, Eobuwie, Oponeo and Babymarkt) were the subject of the study. The author acknowledges, however, that this sample cannot adequately represent the entire cross-border ecommerce industry as it does not reflect any online store outside the EU. To make the conclusions more convincing, data from more cross-border e-commerce need to be collected in the future. Second, observations were conducted only for the three companies based in Poland and one originating from Germany. These observations, therefore, do not reflect online cross-border e-commerce in other European countries. Data reflecting more European countries need to be collected to further investigate the role of retailers' country origin. Third, the load time may vary according to time-of-day, and also period of the year. Fourth, although each online store was observed in terms of the same DNS lookup time, connect time and time-to-first-byte, there are still some unobservable factors across an online store that might have influence for overall speed. Further studies will need to retrieve more data to address this issue.

\section{APPENDIX}

Appendix contains 57 domains from four sets with lookup time, connect time, TTFB time and current IP address.

\begin{tabular}{|c|c|c|c|c|}
\hline Online store & $\begin{array}{l}\text { Lookup } \\
\text { time (s) }\end{array}$ & $\begin{array}{l}\text { Connect } \\
\text { time (s) }\end{array}$ & $\begin{array}{l}\text { TTFB } \\
\text { (s) }\end{array}$ & IP \\
\hline babyaisle.it & 0.005 & 0.053 & 1.685 & 176.119 .53 .127 \\
\hline babyaisle.es & 0.004 & 0.055 & 1.488 & 176.119 .53 .1 \\
\hline babyaisle.cz & 0.005 & 0.057 & 1.462 & 176.119 .53 .127 \\
\hline babyaisle.dk & 0.015 & 0.062 & 1.390 & 104.25 .247 .100 \\
\hline babyaisle.de & 0.013 & 0.080 & 1.542 & 104.25 .138 .110 \\
\hline babyland.pl & 0.128 & 0.187 & 1.508 & 104.25 .180 .101 \\
\hline babyaisle.fr & 0.133 & 0.192 & 1.324 & 104.27 .168 .56 \\
\hline babyaisle.eu & 0.137 & 0.199 & 1.474 & 104.31 .83 .41 \\
\hline eskor.se & 0.004 & 0.053 & 0.370 & 104.16 .227 .90 \\
\hline eavalyne.lt & 0.004 & 0.054 & 0.312 & 104.17 .209 .100 \\
\hline zapatos.es & 0.005 & 0.059 & 0.318 & 104.18 .215 .17 \\
\hline ecipo.hu & 0.015 & 0.065 & 0.325 & 104.16 .86 .10 \\
\hline eobuwie.com.pl & 0.019 & 0.076 & 0.326 & 104.17 .26 .2 \\
\hline epapoutsia.gr & 0.014 & 0.079 & 0.323 & 104.16 .187 .97 \\
\hline chaussures.fr & 0.133 & 0.181 & 0.446 & 104.17 .187 .60 \\
\hline epantofi.ro & 0.133 & 0.186 & 0.515 & 104.16 .135 .30 \\
\hline eschuhe.ch & 0.132 & 0.187 & 0.450 & 104.16 .124 .11 \\
\hline eobuv.com.ua & 0.132 & 0.187 & 0.445 & 104.18.212.19 \\
\hline efootwear.eu & 0.135 & 0.188 & 0.463 & 104.18.236.59 \\
\hline eobuv.sk & 0.131 & 0.188 & 0.431 & 104.18 .72 .16 \\
\hline eobuv.cz & 0.130 & 0.189 & 0.438 & 104.16 .86 .67 \\
\hline escarpe.it & 0.131 & 0.190 & 0.440 & 104.16 .158 .98 \\
\hline obuvki.bg & 0.141 & 0.190 & 0.453 & 104.17 .44 .78 \\
\hline eobuv.com & 0.134 & 0.194 & 0.461 & 104.18 .69 .27 \\
\hline oponeo.fr & 0.005 & 0.059 & 0.848 & 91.206 .7 .197 \\
\hline oponeo.cz & 0.004 & 0.061 & 0.976 & 91.206 .7 .194 \\
\hline oponeo.pl & 0.005 & 0.064 & 0.471 & 91.206 .7 .26 \\
\hline oponeo.hu & 0.005 & 0.065 & 0.770 & 91.206 .7 .199 \\
\hline oponeo.com & 0.005 & 0.067 & 0.364 & 91.206 .7 .121 \\
\hline pneus-oponeo.be & 0.005 & 0.068 & 0.765 & 91.206 .7 .147 \\
\hline oponeo.ie & 0.013 & 0.068 & 0.889 & 91.206 .7 .196 \\
\hline oponeo.ch & 0.004 & 0.068 & 0.943 & 91.206 .7 .19 \\
\hline oponeo.at & 0.013 & 0.070 & 0.958 & 91.206 .7 .231 \\
\hline oponeo.com.tr & 0.016 & 0.071 & 0.570 & 91.206 .7 .21 \\
\hline $\begin{array}{l}\text { banden- } \\
\text { oponeo.be }\end{array}$ & 0.005 & 0.071 & 1.036 & 91.206 .7 .177 \\
\hline oponeo.es & 0.013 & 0.072 & 0.629 & 91.206 .7 .187 \\
\hline oponeo.sk & 0.013 & 0.072 & 0.765 & 91.206 .7 .142 \\
\hline oponeo.de & 0.013 & 0.073 & 0.753 & 91.206 .7 .182 \\
\hline oponeo.co.uk & 0.014 & 0.074 & 0.443 & 91.206 .7 .189 \\
\hline pneus-oponeo.ch & 0.015 & 0.081 & 0.693 & 91.206 .7 .100 \\
\hline oponeo.nl & 0.013 & 0.084 & 0.758 & 91.206 .7 .198 \\
\hline oponeo.it & 0.037 & 0.094 & 0.486 & 91.206 .7 .188 \\
\hline pinkorblue.cz & 0.006 & 0.071 & 0.509 & 37.49 .153 .153 \\
\hline baby-markt.ch & 0.004 & 0.073 & 0.428 & 37.49 .153 .153 \\
\hline pinkorblue.be & 0.005 & 0.076 & 0.455 & 37.49 .153 .153 \\
\hline rosaoazul.es & 0.015 & 0.082 & 0.456 & 37.49 .153 .153 \\
\hline pinkorblue.dk & 0.015 & 0.105 & 0.412 & 37.49 .153 .153 \\
\hline baby-markt.at & 0.005 & 0.127 & 0.416 & 37.49 .153 .153 \\
\hline pinkorblue.se & 0.130 & 0.197 & 0.608 & 37.49 .153 .153 \\
\hline pinkorblue.fi & 0.130 & 0.199 & 0.592 & 37.49 .153 .153 \\
\hline baby-markt.com & 0.132 & 0.200 & 0.613 & 37.49 .153 .153 \\
\hline pinkorblue.nl & 0.134 & 0.201 & 0.574 & 37.49 .153 .153 \\
\hline pinkorblue.no & 0.130 & 0.204 & 0.658 & 37.49 .153 .153 \\
\hline pinkorblue.it & 0.135 & 0.206 & 0.563 & 37.49 .153 .153 \\
\hline pinkorblue.pl & 0.134 & 0.208 & 0.540 & 37.49 .153 .153 \\
\hline roseoubleu.fr & 0.264 & 0.366 & 0.718 & 37.49 .153 .153 \\
\hline babymarkt.de & 0.522 & 0.638 & 0.955 & 37.49 .153 .153 \\
\hline
\end{tabular}




\section{REFERENCES}

[1] S.-L. Huang and Y.-C. Chang, "Cross-border e-commerce: consumers' intention to shop on foreign websites," Internet Res., vol. 29, no. 6, pp. 1256-1279, Dec. 2019, doi: 10.1108/INTR-11-2017-0428.

[2] E. Gomez-Herrera, B. Martens, and G. Turlea, "The drivers and impediments for cross-border e-commerce in the EU," Inf. Econ. Policy, vol. 28, pp. 83-96, Sep. 2014, doi: 10.1016/j.infoecopol.2014.05.002.

[3] B. Lu and H. Wang, "Research on the Competitive Strategy of CrossBorder E-Commerce Comprehensive Pilot Area Based on the Spatial Competition," Sci. Program., vol. 2016, no. 5, pp. 1-9, Oct. 2016, doi: 10.1155/2016/6216052.

[4] N. Poggi, D. Carrera, R. Gavaldà, E. Ayguadé, and J. Torres, “A methodology for the evaluation of high response time on E-commerce users and sales," Inf. Syst. Front., vol. 16, no. 5, pp. 867-885, Nov. 2014, doi: 10.1007/s10796-012-9387-4.

[5] X. S. Wang, A. Balasubramanian, A. Krishnamurthy, and D. Wetherall, "Demystifying Page Load Performance with WProf," in 10th USENIX Symposium on Networked Systems Design and Implementation, 2013, pp. 473-485.

[6] E. Halepovic, J. Pang, and O. Spatscheck, "Can you GET Me Now? Estimating the Time-to-First-Byteof HTTP Transactions with Passive Measurements," in Proceedings of the 2012 ACM conference on Internet measurement conference, 2012, p. 115, doi: 10.1145/2398776.2398789.

[7] A. Vakali and G. Pallis, "Content Delivery Networks: Status and Trends," IEEE Internet Comput., vol. 7, no. 6, pp. 68-74, 2003, doi: 10.1109/MIC.2003.1250586.

[8] R. Tewari, H. M. Vin, A. Dan, and D. Sitaram, "Resource-based Caching for Web Servers Department of Computer Sciences The University of Texas at Austin y IBM Research Division," Multimed. Comput. Netw., vol. 3310, pp. 191-204, 1998.

[9] H. F. Nielsen, J. Gettys, A. Baird-Smith, E. Prud'hommeaux, H. W. Lie, and C. Lilley, "Network performance effects of HTTP/1.1, CSS1, and PNG," Comput. Commun. Rev., vol. 27, no. 4, pp. 155-166, 1997, doi: 10.1145/263109.263157.

[10] H. de Saxce, I. Oprescu, and Y. Chen, "Is HTTP/2 really faster than HTTP/1.1?," in 2015 IEEE Conference on Computer Communications Workshops, $2015, \quad$ pp. $293-299, \quad$ doi: 10.1109/INFCOMW.2015.7179400.

[11] J. Andjarwirawan, I. Gunawan, and E. B. Kusumo, "Varnish Web Cache Application Evaluation," in Intelligence in the Era of Big Data, R. Intan, C. Chi, H. Palit, and L. Santoso, Eds. Springer, Berlin, Heidelberg, 2015, pp. 404-410.

[12] A. Miklošík, P. Červenka, and I. Hlavatý, "Marketing identity impact of accelerated mobile pages format on corporate web sites," in Marketing Identity Brands we love - part I, 2016, pp. 204-214.

[13] A. Subramanya, "Image compression technique," IEEE Potentials, vol. 20, no. 1, pp. 19-23, 2001, doi: 10.1109/45.913206.

[14] D. Duce, I. Herman, and B. Hopgood, "Web 2D Graphics: State-of-theArt," Comput. Graph. Forum, vol. 21, no. 1, pp. 43-65, 2002.

[15] Y. Sakamoto, S. Matsumoto, S. Tokunaga, S. Saiki, and M. Nakamura, "Empirical study on effects of script minification and HTTP compression for traffic reduction," in Third International Conference on Digital Information, Networking, and Wireless Communications (DINWC), 2015, pp. 127-132, doi: 10.1109/DINWC.2015.7054230.

[16] S. Souders, "High Performance Web Sites," Quеue, vol. 6, no. 6, pp. 30-37, 2008.

[17] Z. Nagy, "Improved Speed on Intelligent Web Sites," in Recent Advances in Computer Science, O. Nakov, P. Borovska, A. Antonio, V. Mladenov, L. Zinchenko, and A. Fuentes-Penna, Eds. WSEAS Press, 2013, pp. 215-220.

[18] Tongwei Ren, Yanwen Guo, Gangshan Wu, and Fuyan Zhang, "Constrained sampling for image retargeting," in 2008 IEEE International Conference on Multimedia and Expo, 2008, pp. 13971400, doi: 10.1109/ICME.2008.4607705.

[19] K. Matsudaira, "Making the mobile web faster," Commun. ACM, vol. 56, no. 3, p. 56, Mar. 2013, doi: 10.1145/2428556.2428572.

[20] K. Zarifis, M. Holland, M. Jain, E. Katz-Bassett, and R. Govindan, "Modeling HTTP/2 Speed from HTTP/1 Traces," in Lecture Notes in
Computer Science, vol. 9631, T. Karagiannis and X. Dimitropoulos, Eds. Springer, Cham, 2016, pp. 233-247.

[21] J. Spiesser and L. Kitchen, "Optimization of html automatically generated by wysiwyg programs," in Proceedings of the 13th conference on World Wide Web, 2004, pp. 355-364, doi: 10.1145/988672.988720.

[22] M. Wickham, "Lazy Loading Images," in Practical Android, Berkeley, CA: Apress, 2018, pp. 47-84.

[23] E. Cohen and H. Kaplan, "Proactive caching of DNS records: addressing a performance bottleneck," Comput. Networks, vol. 41, no. 6, pp. 707726, Apr. 2003, doi: 10.1016/S1389-1286(02)00424-3.

[24] Y. Deng and S. Manoharan, "Review and analysis of web prefetching," in 2015 IEEE Pacific Rim Conference on Communications, Computers and Signal Processing, 2015, pp. 40-45, doi: 10.1109/PACRIM.2015.7334806.

[25] R. Queirós, "CSS Preprocessing: Tools and Automation Techniques," Information, vol. 9, no. 1, p. 17, Jan. 2018, doi: 10.3390/info9010017.

[26] M. Selakovic and M. Pradel, "Performance issues and optimizations in JavaScript," in Proceedings of the 38th International Conference on Software Engineering, 2016, pp. 61-72, doi: 10.1145/2884781.2884829.

[27] B. Molina, C. E. Palau, and M. Esteve, "Modeling content delivery networks and their performance," Comput. Commun., vol. 27, no. 15, pp. 1401-1411, Sep. 2004, doi: 10.1016/j.comcom.2004.05.012.

[28] N. Bartolini, E. Casalicchio, and S. Tucci, "A Walk through Content Delivery Networks," in Performance Tools and Applications to Networked Systems, vol. 2965, E. Calzarossa, MC and Gelenbe, Ed. 2004, pp. 1-25.

[29] O. Ercetin and L. Tassiulas, "Pricing strategies for differentiated services content delivery networks," Comput. Networks, vol. 49, no. 6, pp. 840-855, Dec. 2005, doi: 10.1016/j.comnet.2005.03.001.

[30] G. Pallis and A. Vakali, "Insight and perspectives for content delivery networks," Commun. ACM, vol. 49, no. 1, pp. 101-106, Jan. 2006, doi: 10.1145/1107458.1107462.

[31] H. Yin, X. Liu, G. Min, and C. Lin, "Content delivery networks: A bridge between emerging applications and future IP networks," IEEE Netw., vol. 24, no. 4, pp. 52-56, 2010, doi: 10.1109/MNET.2010.5510919.

[32] M. A. Kaafar, S. Berkovsky, and B. Donnet, "On the potential of recommendation technologies for efficient content delivery networks," ACM SIGCOMM Comput. Commun. Rev., vol. 43, no. 3, p. 74, Jul. 2013, doi: 10.1145/2500098.2500109.

[33] M. Wang et al., "An overview of cloud based content delivery networks: Research dimensions and state-of-the-Art," in Lecture Notes in Computer Science, vol. 9070, A. Hameurlain, A and Kung, J and Wagner, R and Sakr, S and Wang, L and Zomaya, Ed. 2015, pp. 131158.

[34] H. Yin, B. Qiao, Y. Luo, C. Tian, and Y. R. Yang, "Demystifying commercial content delivery networks in China," Concurr. Comput. , vol. 27, no. 13, pp. 3523-3538, Sep. 2015, doi: 10.1002/cpe.3464.

[35] V. Stocker, G. Smaragdakis, W. Lehr, and S. Bauer, "The growing complexity of content delivery networks: Challenges and implications for the Internet ecosystem," Telecomm. Policy, vol. 41, no. 10, pp. 1003-1016, Nov. 2017, doi: 10.1016/j.telpol.2017.02.004.

[36] Y.-H. Hsiao, M.-C. Chen, and W.-C. Liao, "Logistics service design for cross-border E-commerce using Kansei engineering with text-miningbased online content analysis," Telemat. Informatics, vol. 34, no. 4, pp. 284-302, Jul. 2017, doi: 10.1016/j.tele.2016.08.002.

[37] M. Giuffrida, R. Mangiaracina, A. Perego, and A. Tumino, "Crossborder B2C e-commerce to Greater China and the role of logistics: a literature review," Int. J. Phys. Distrib. Logist. Manag., vol. 47, no. 9, pp. 772-795, 2017, doi: 10.1108/ijpdlm-08-2016-0241.

[38] Y. Wang, Y. Wang, and S. Lee, "The Effect of Cross-Border ECommerce on China's International Trade: An Empirical Study Based on Transaction Cost Analysis," Sustainability, vol. 9, no. 11, p. 2028, Nov. 2017, doi: 10.3390/su9112028.

[39] Y. Wang, F. Jia, T. Schoenherr, and Y. Gong, "Supply Chain-Based Business Model Innovation: The Case of a Cross-Border E-Commerce Company," Sustainability, vol. 10, no. 12, p. 4362, Dec. 2018, doi: $10.3390 /$ su10124362. 
[40] H. Li and X. Miao, "Research on the status quo and operation model of logistics of crossborder e-commerce in China," Agro Food Ind. Hi. Tech., vol. 28, no. 3, pp. 2845-2849, 2017.

[41] N. Chen and J. Yang, "Mechanism of government policies in crossborder e-commerce on firm performance and implications on $\mathrm{m}$ commerce," Int. J. Mob. Commun., vol. 15, no. 1, p. 69, 2016, doi: 10.1504/ijmc.2017.080578.

[42] L. Feng, J. Ma, Y. Wang, and J. Yang, "Supply chain downstream strategic cost evaluation using L-COPRAS method in cross-border Ecommerce," Int. J. Comput. Intell. Syst., vol. 10, no. 1, p. 815, Jan. 2017, doi: 10.2991/ijcis.2017.10.1.54.

[43] R. Qi, "Application of Improved Collaborative Filtering Algorithm in Cross Border E-commerce Recommender System," Chim. Oggi-Chem. Today, vol. 36, no. 6, pp. 1774-1776, Dec. 2018.

[44] S. Ma, Y. Chai, and H. Zhang, "Rise of Cross-border E-commerce Exports in China," China World Econ., vol. 26, no. 3, pp. 63-87, May 2018, doi: 10.1111/cwe.12243.

[45] S. Ma, Y. Chai, J. Wang, and Y. Duan, "New digital infrastructure, cross-border e-commerce and global vision of creating electronic world trade platform," Glob. Trade Cust. J., vol. 13, no. 4, pp. 157-167, 2018.

[46] J. Rong and D. Zhong, "Influence factors of customer satisfaction in cross-border e-commerce," J. Discret. Math. Sci. Cryptogr., vol. 21, no. 6, pp. 1281-1286, 2018, doi: 10.1080/09720529.2018.1526401.

[47] A. J. Lin, E. Y. Li, and S.-Y. Lee, "Dysfunctional customer behavior in cross-border e-commerce: A Justice-affect-behavior model," J. Electron. Commer. Res., vol. 19, no. 1, pp. 36-54, 2018.

[48] G. H. Gessner and C. R. Snodgrass, "Designing e-commerce cross- border distribution networks for small and medium-size enterprises incorporating Canadian and U.S. trade incentive programs," Res. Transp. Bus. Manag., vol. 16, pp. 84-94, Sep. 2015, doi: 10.1016/j.rtbm.2015.07.005.

[49] A. Kawa and W. Zdrenka, "Conception of Integrator in Cross-Border ECommerce," Logforum, vol. 12, no. 1, pp. 63-73, 2016, doi: 10.17270/j.log.2016.1.6.

[50] Á. Valarezo, T. Pérez-Amaral, T. Garín-Muñoz, I. Herguera García, and R. López, "Drivers and barriers to cross-border e-commerce: Evidence from Spanish individual behavior," Telecomm. Policy, vol. 42, no. 6, pp. 464-473, Jul. 2018, doi: 10.1016/j.telpol.2018.03.006.

[51] F. Aulkemeier, M. E. Iacob, and J. van Hillegersberg, "An architectural perspective on service adoption: A platform design and the case of pluggable cross-border trade compliance in e-commerce," J. Organ. Comput. Electron. Commer., vol. 27, no. 4, pp. 325-341, 2017, doi: 10.1080/10919392.2017.1363588.

[52] A. Strzelecki, "Key Features of E-Tailer Shops in Adaptation to CrossBorder E-Commerce in the EU," Sustainability, vol. 11, no. 6, p. 1589, Mar. 2019, doi: 10.3390/su11061589.

[53] A. M. Habib and M. Abrams, "Analysis of Sources of Latency in Downloading Web Pages," in WebNet World Conference on the WWW and Internet, 2000, pp. 227-232.

[54] T. Osbourn, "Testing DNS Speeds," 2018. [Online]. Available: https://tosbourn.com/testing-dns-speeds/. [Accessed: 30-Mar-2020].

[55] J. Fox, "Find the Time to First Byte Using Curl," 2011. [Online]. Available: https://www.jonefox.com/blog/2011/10/10/find-the-time-tofirst-byte-using-curl/comment-page-1/. [Accessed: 30-Mar-2020]. 